\title{
S-1 chemotherapy and intensity-modulated radiotherapy after D1/D2 lymph node dissection in patients with node-positive gastric cancer: a phase I/II study
}

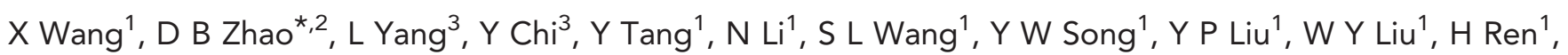
T Zhang ${ }^{1}$, J Y Wang ${ }^{1}$, X S Chen ${ }^{1}$, H Fang ${ }^{1}$, W H Wang ${ }^{4}, Y$ X Li ${ }^{1}$ and J Jin ${ }^{*}, 1$

${ }^{1}$ Department of Radiation Oncology, Cancer Hospital and Institute, National Cancer Center, Chinese Academy of Medical Sciences (CAMS) and Peking Union Medical College, Beijing 100021, People's Republic of China; ${ }^{2}$ Department of Pancrea-gastric Surgery, Cancer Hospital and Institute, National Cancer Center, Chinese Academy of Medical Sciences (CAMS) and Peking Union Medical College, Beijing 100021, People's Republic of China; ${ }^{3}$ Department of Medical Oncology, Cancer Hospital and Institute, National Cancer Center, Chinese Academy of Medical Sciences (CAMS) and Peking Union Medical College, Beijing 100021, People's Republic of China and ${ }^{4}$ Department of Radiation Oncology, Beijing Cancer Hospital, Beijing 100142, People's Republic of China

Background: This phase I/II clinical trial investigated S-1 administered with intensity-modulated radiotherapy (IMRT) as adjuvant therapy for node-positive gastric cancer. Patients had undergone radical resection and D1/D2 lymph node dissection.

Methods: In phase I, patients received adjuvant chemoradiotherapy of IMRT (45Gy in 25 fractions) with concurrent S-1 administered on a dose-escalation schedule to determine the recommended dose (RD). In phase II, the safety and efficacy of the RD of S-1 combined with IMRT were assessed.

Results: We consecutively enrolled 73 patients (56 men; median age, 53 years; range, 29-73 years) and the phase I portion of the study included 27 patients. The RD of S-1 administered concomitantly with IMRT was $80 \mathrm{mg} \mathrm{m}^{-2}$ day ${ }^{-1}$ orally, twice daily. The phase II analysis included 52 patients (46 new patients plus 6 from phase I). 8 patients (15.4\%) developed grade 3 or 4 toxicities. There were 21 recurrence events and 15 deaths (1 bowel obstruction, 14 gastric cancer). Three-year disease-free survival and overall survival were $62.2 \%$ (95\% confidence interval (Cl), 48.5-75.9) and 70.0\% (95\% Cl, 56.3-83.7), respectively. The median time to recurrence was 17.5 months (range, 3.8-42.0). The median time from recurrence to death was 7.0 months (range, 1.5-28.7).

Conclusions: S-1 combined with IMRT adjuvant chemoradiotherapy is safe and efficacious for advanced gastric cancer.

Two large-scale randomised phase III studies, CLASSIC (Adjuvant Chemotherapy Trial of Capecitabine Plus Oxaliplatin for Gastric Cancer) and ACTS-GC (Adjuvant Chemotherapy Trial of S-1 for Gastric Cancer), have demonstrated that adjuvant chemotherapy reduces the risk of relapse and improves overall survival (OS) in patients with locally advanced gastric cancer after D2 lymph node dissection (LND) (Sakuramoto et al, 2007; Bang et al, 2012). Although the benefit of this approach following D0 or D1 LND has

*Correspondence: Professor D-B Zhao; E-mail: dbzhao2003@sina.com or Professor J Jin; E-mail: jingjin1025@163.com

This study was orally presented in part at the 58th Annual Meeting of the American Society of Radiation Oncology, 25-28 September 2016 in Boston, MA, USA.

Received 25 July 2017; revised 27 October 2017; accepted 31 October 2017; published online 12 December 2017

(C) 2018 Cancer Research UK. All rights reserved 0007-0920/18 
not been documented in randomised clinical trials, adjuvant chemoradiotherapy (ACRT) is considered the standard of treatment for this subpopulation of gastric cancer patients as demonstrated by the results of INT-0116 (ACRT Trial for Gastric Cancer; Macdonald et al, 2001).

The benefit of ACRT for patients with D2 LND in locally advanced gastric cancer remains controversial. The ARTIST trial, which was the first randomised phase III trial in Asian patients undergoing D2 LND that compared the efficacy of capecitabine plus cisplatin to capecitabine with concurrent radiotherapy, failed to demonstrate that adding ACRT could improve disease-free survival (DFS) and OS (Lee et al, 2012). However, the results for a subgroup of patients with node-positive gastric cancer suggested a significant DFS effect of ACRT (Park et al, 2015). Therefore, adding ACRT to adjuvant chemotherapy should be considered to improve clinical outcomes for this group of patients.

S-1 is a combination drug that sustains higher plasma concentrations of 5-fluorouracil (5-FU) and reduces its gastrointestinal toxicity (Schöffski, 2004). The drug has yielded high tumour response rates $(>40 \%)$ when administered as monotherapy in phase II studies (Koizumi et al, 2000) and has shown noninferiority to infusional 5-FU or UFT (a combination of tegafur and uracil) in phase III trials for patients with advanced gastric cancer (Tsuburaya et al, 2014).

Several studies have proved that intensity-modulated radiotherapy (IMRT) is superior to two- or three-dimensional radiotherapy, as it provides a more conformal and homogeneous dose to the planning target volume and accordingly minimises the risk of toxicity (Trip et al, 2014). The aims of this phase I/II clinical trial were to determine (a) the optimal dose of S-1 when administered in combination with IMRT and (b) the safety and efficacy of this combination as an adjuvant therapy for patients with node-positive gastric cancer who had undergone radical resection and D1/D2 LND.

\section{MATERIALS AND METHODS}

Eligibility. Patients were eligible for inclusion in the study if they met the followings: (1) no neoadjuvant treatment, (2) radical surgery with D1/D2 LND, (3) pathologically confirmed adenocarcinoma, (4) positive lymph nodes (PLNs) on postoperative pathological examination, (5) World Health Organisation performance status $\leqslant 1$ and age $\leqslant 75$ years, (6) haemoglobin level $\geqslant 10.0 \mathrm{gl}^{-1}$, leukocyte count $\geqslant 3.5 \times 10^{9} 1^{-1}$, neutrophil count $\geqslant 1.5 \times 10^{9} 1^{-1}$, platelet count $\geqslant 100 \times 10^{9} 1^{-1}$, and normal liver and kidney function.

Antacid and gastric mucosa protectants were administered on a prophylactic basis. Antiemetic and antidiarrhoeal agents were prescribed when needed. Follow-up assessments included clinical examination, biochemical tests, tests for tumour markers, abdominopelvic computed tomography (CT), and chest radiography and/or CT. Patients were followed up once every 3 months for the first 2 years and every 6 months thereafter.

Both the phase I and phase II studies were approved by the ethics committee of our hospital and were registered at clinicaltrials.gov (NCT01291407 and NCT02296658). All patients signed informed consent forms.

Radiotherapy. A total irradiation dose of $45 \mathrm{~Gy}$ was delivered in daily 1.8-Gy fractions (5 days a week over 5 weeks). Patients were required to be on an empty stomach for $4 \mathrm{~h}$ before the CT simulation and take an oral positive contrast $(300 \mathrm{ml}) 30 \mathrm{~min}$ before the simulation to make the small intestine visible. To decrease variability in distention due to gastric filling, a standard meal (300 $\mathrm{ml}$ of ready-to-eat canned porridge) was given to the patients $15 \mathrm{~min}$ before CT scanning and before each treatment.
Patients were placed in a supine position with thermoplastic immobilisation during IMRT with a 6-MV photon beam.

The delineation of the clinical target volume depended on the extension and location of the primary tumour and the guidelines for the involved lymph node region issued by the Japanese Gastric Cancer Association (Japanese Gastric Cancer Association, 1998) and has been published in our previous study (Supplementary Information; Wang et al, 2014). The remnant stomach was not routinely included within the radiation field. Dose constraints for organs at risk have also been reported in our previous study (Wang et al, 2014).

Chemotherapy. S-1 was administered twice daily on radiotherapy days, in a dose-escalation schedule of $30 \mathrm{mg} \mathrm{m}^{-2}$ day $^{-1}$ (level I), $40 \mathrm{mg} \mathrm{m}^{-2}$ day $^{-1}$ (level II), $50 \mathrm{mg} \mathrm{m}^{-2}$ day $^{-1}$ (level III), $60 \mathrm{mg} \mathrm{m}^{-2}$ day ${ }^{-1}$ (level IV), $70 \mathrm{mg} \mathrm{m}^{-2}$ day $^{-1}$ (level V), and $80 \mathrm{mg} \mathrm{m}^{-2}$ day $^{-1}$ (level VI).

A maximum 6 months of adjuvant chemotherapy with platinum fluoropyrimidine-based combination regimens were allowed to be performed before or after ACRT depending on the performance status, medical comorbidities, and toxicity profile of the patient.

Study design and statistical analysis. Phase $I$. The goal of phase I was to estimate the maximum tolerated dose (MTD) and the doselimiting toxicity (DLT) of S-1 when administered concurrently with IMRT and to determine the recommended dose (RD) of S-1 for patients with node-positive gastric cancer. Adverse events were coded in accordance with the National Cancer Institute Common Terminology Criteria for Adverse Events, version 3.0. The administration of S-1 was terminated without dose modification if DLT occurred.

DLT was defined as any of the following: grade 4 leukopenia or neutropenia, grade 3-4 thrombocytopenia or anaemia, and grade 3-4 non-haematological toxicity. If DLT occurred in one of the first three patients, three additional patients would be assigned to receive the same dose level. If none of the first three patients initially receiving a given dose level developed DLT, or if only one of the six patients developed DLT, the dose was to be increased to the next level. If a second patient experienced a DLT at the same level, then the escalation was to be stopped, and the MTD would be defined as the level at which the DLT occurred and was considered as RD.

Phase II. The aim of the phase II trial was to determine the safety and efficacy of the RD of S-1 combined with IMRT. The primary end point was the 3 -year DFS. The secondary end points were OS and toxicity. The 3 -year DFS rate was predicted to be improved from 50 to $70 \%$ based on the results of INT-0116, with one-sided $\alpha=0.05$ and $80 \%$ power. A total of 43 patients were required. Assuming a dropout rate of $15 \%, 50$ patients were needed for the phase II study.

Locoregional recurrence was defined as relapse at the anastomosis site, gastric remnant, duodenal stump, tumour bed, or regional lymph nodes within the radiation field. Relapse in the lymph nodes outside the radiation field, peritoneal implantation, and metastasis to the liver or any other extra-abdominal site were regarded as distant metastases. DFS was defined as the interval from the date of the surgery to the date of recurrence or death from any cause. Survival curves were calculated with the Kaplan-Meier method by means of the SPSS for Windows program, version 20.0 (IBM SPSS, Armonk, NY, USA).

\section{RESULTS}

Patient characteristics. Between May 2010 and August 2015, 73 patients were consecutively recruited (Phase I, $n=27$, from May 2010 to June 2013). The patient characteristics are presented in Table 1. All patients had metastatic lymph nodes; the median number of PLN was 9 (range, 1-45 nodes); and the median 
number of lymph nodes resected was 31 (range, 8-79 nodes). All patients received various adjuvant chemotherapy regimens based on oxaliplatin and 5-FU analogues, with a median of 6 cycles (range, 2-10 cycles) before or after ACRT, as follows: oxaliplatin, S-1 $(n=44,60.3 \%)$; paclitaxel/docetaxel, oxaliplatin, and capecitabine/S-1 $(n=19,26.0 \%)$; oxaliplatin, capecitabine $(n=6,8.2 \%)$; and oxaliplatin, 5 -FU, leucovorin $(n=4,5.5 \%)$. The median time from surgery to the start of radiotherapy was 5.2 months (range, 1.5-7 months).

Toxicity and treatment compliance. Phase I. The phase I portion of the study enrolled 27 patients; the toxicities observed in these patients have been summarised in Table 2. At dose level I, one patient experienced grade- 3 anorexia and nausea and finished ACRT with a total irradiation dose of $39.6 \mathrm{~Gy}$. At dose level III, one patient developed grade-3 thrombocytopenia and was given a chemotherapy break of 6 weekdays but completed the whole

\section{Table 1. Patient characteristics}

\begin{tabular}{|c|c|c|c|c|}
\hline \multirow[b]{2}{*}{ Characteristic } & \multicolumn{2}{|c|}{ Total $(n=73)$} & \multicolumn{2}{|c|}{$\begin{array}{l}\text { Patients given RD } \\
\quad(n=52)\end{array}$} \\
\hline & $N$ & $\%$ & $N$ & $\%$ \\
\hline Age (years), median (range) & \multicolumn{2}{|c|}{$53(29-73)$} & \multicolumn{2}{|c|}{$53(29-73)$} \\
\hline Men & 56 & 76.7 & 38 & 73.1 \\
\hline $\begin{array}{l}\text { Tumour size }(\mathrm{cm}), \text { median } \\
\text { (range) }\end{array}$ & \multicolumn{2}{|c|}{$4.5(2-18)$} & \multicolumn{2}{|c|}{$4.0(2-11.5)$} \\
\hline $\begin{array}{l}\text { Location of primary tumour } \\
\text { Upper } 1 / 3 \text { of stomach } \\
\text { Middle } 1 / 3 \text { of stomach } \\
\text { Lower } 1 / 3 \text { of stomach } \\
\geqslant 2 \text { sites involved }\end{array}$ & $\begin{array}{l}11 \\
10 \\
39 \\
13\end{array}$ & $\begin{array}{l}15.1 \\
13.7 \\
53.4 \\
17.8\end{array}$ & $\begin{array}{r}6 \\
8 \\
27 \\
11\end{array}$ & $\begin{array}{l}11.5 \\
15.4 \\
51.9 \\
21.2\end{array}$ \\
\hline Positive LNs, median (range) & \multicolumn{2}{|c|}{$9(1-45)$} & \multicolumn{2}{|c|}{$11.5(1-45)$} \\
\hline LNs resected, median (range) & \multicolumn{2}{|c|}{$31(8-79)$} & \multicolumn{2}{|c|}{$34(14-79)$} \\
\hline LN ratio, median (range) & \multicolumn{2}{|c|}{$0.32(0.05-0.90)$} & \multicolumn{2}{|c|}{$0.30(0.05-0.90)$} \\
\hline $\begin{array}{l}\text { Extent of dissection } \\
\text { D1 } \\
\text { D2 }\end{array}$ & $\begin{array}{l}20 \\
53\end{array}$ & $\begin{array}{l}27.4 \\
72.6\end{array}$ & $\begin{array}{l}10 \\
42\end{array}$ & $\begin{array}{l}19.2 \\
80.8\end{array}$ \\
\hline $\begin{array}{l}\text { Lauren type } \\
\text { Intestinal type } \\
\text { Diffuse type } \\
\text { Mixed type } \\
\text { Undetermined }\end{array}$ & $\begin{array}{l}12 \\
27 \\
20 \\
14\end{array}$ & $\begin{array}{l}16.4 \\
37.0 \\
27.4 \\
19.2\end{array}$ & $\begin{array}{r}8 \\
20 \\
14 \\
10\end{array}$ & $\begin{array}{l}15.4 \\
38.5 \\
26.9 \\
19.2\end{array}$ \\
\hline $\begin{array}{l}\text { Tumour differentiation } \\
\text { Good } \\
\text { Moderate } \\
\text { Poor }\end{array}$ & $\begin{array}{r}1 \\
9 \\
63\end{array}$ & $\begin{array}{c}1.4 \\
12.4 \\
86.2\end{array}$ & $\begin{array}{r}1 \\
7 \\
44\end{array}$ & $\begin{array}{c}1.9 \\
13.4 \\
84.7\end{array}$ \\
\hline $\begin{array}{l}\text { Lymphatic/vascular invasion } \\
\text { Present } \\
\text { Absent }\end{array}$ & $\begin{array}{l}40 \\
33\end{array}$ & $\begin{array}{l}54.8 \\
45.2\end{array}$ & $\begin{array}{l}30 \\
22\end{array}$ & $\begin{array}{l}57.7 \\
42.3\end{array}$ \\
\hline $\begin{array}{l}\text { Perineural invasion } \\
\text { Present } \\
\text { Absent }\end{array}$ & $\begin{array}{l}35 \\
38\end{array}$ & $\begin{array}{l}47.9 \\
52.1\end{array}$ & $\begin{array}{l}32 \\
20\end{array}$ & $\begin{array}{l}61.5 \\
38.5\end{array}$ \\
\hline $\begin{array}{l}\text { Stage (AJCC Seventh) } \\
\text { Ila } \\
\| \mathrm{lb} \\
\|\| \mathrm{a} \\
\|\| \mathrm{b} \\
\|\| \mathrm{c}\end{array}$ & $\begin{array}{r}2 \\
6 \\
15 \\
35 \\
15\end{array}$ & $\begin{array}{c}2.7 \\
8.2 \\
20.6 \\
47.9 \\
20.6\end{array}$ & $\begin{array}{r}0 \\
3 \\
10 \\
25 \\
14\end{array}$ & $\begin{array}{c}0 \\
5.8 \\
19.2 \\
48.1 \\
26.9\end{array}$ \\
\hline $\begin{array}{l}\text { Stage (AJCC Sixth) } \\
\text { Ib } \\
\| \\
\|\| \mathrm{a} \\
\| \mathrm{llb} \\
\mathrm{IV}\end{array}$ & $\begin{array}{r}2 \\
17 \\
31 \\
7 \\
16\end{array}$ & $\begin{array}{c}2.7 \\
23.3 \\
42.5 \\
9.6 \\
21.9\end{array}$ & $\begin{array}{r}0 \\
10 \\
22 \\
6 \\
14\end{array}$ & $\begin{array}{c}0 \\
19.2 \\
42.3 \\
11.5 \\
26.9\end{array}$ \\
\hline
\end{tabular}

radiotherapy dose. At level VI, none of the first three patients developed a DLT. Three more patients were treated at this level, but none of them had a DLT. Therefore, level VI (S-1, $80 \mathrm{mg} \mathrm{m}^{-2}$ day $^{-1}$, on radiotherapy days) was deemed to be the MTD and RD for the phase II study.

Phase II. An additional 46 patients were enrolled in the phase II portion of the trial. Six patients treated with the $\mathrm{RD}$ in the phase I portion were also included in the phase II analysis for a total of 52 patients. Of the 52 patients, $8(15.4 \%)$ developed grade 3 or 4 toxicities (Table 3 ). The most common grade 3-4 toxicities were leukopenia (6 patients, $11.5 \%)$, anorexia $(5,9.6 \%)$, and nausea (5, 9.6\%). No treatment-related deaths occurred.

Three patients (5.8\%, 3 out of 52) stopped ACRT and received total doses of 39.6, 23.4, and 41.4 Gy; they discontinued ACRT because of grade 3 neutropenia with fever, grade- 4 nausea and vomiting, and personal reasons, respectively. Of the 52 patients, 13 (25\%) discontinued the S-1 treatment protocol. In addition to the reasons for the discontinuation of ACRT mentioned above, 10 other patients did not complete the entire course of S-1 treatment because of the following reasons: thrombocytopenia (maximum grade, 3), 4 patients; vomiting (maximum grade, 3), 3 patients; leukopenia (maximum grade, 3), 2 patients; and gastritis (maximum grade, 3), 1 patient. The mean length of the chemotherapy break in these 13 patients was 6.7 days (range, 3-12 days).

Tumour relapse and patient survival at $\mathrm{RD}$ in phases $\mathrm{I}$ and II. The median follow-up duration was 37.6 months (range, 21.855.6 months) in the 52 patients who received the $\mathrm{RD}$ in phases I and II. Among them, 21 recurrence events and 15 deaths occurred (one due to bowel obstruction and the others due to gastric cancer). The DFS at 3 years, the primary end point of phase II, was $62.2 \%$ (95\% confidence interval (CI), 48.5-75.9). The 3-year OS, locoregional recurrence-free survival (LRFS), and distant metastasis-free survival were $70.0 \%$ (95\% CI, 56.3-83.7), $92.2 \%$ (95\% CI, 84.9-99.5), and 63.5\% (95\% CI, 49.8-77.2), respectively.

Five patients developed locoregional recurrence. Distant metastasis occurred in 20 patients $(38.5 \%, 20$ out of 52$)$. The most common distant metastasis was peritoneal implantation, which occurred in 11 patients $(21.2 \%, 11$ out of 52$)$. The median time to recurrence was 17.5 months (range, 3.8-42.0 months). The median time from recurrence to death was 7.0 months (range, 1.5-28.7 months).

\section{DISCUSSION}

The results of the present study suggest that ACRT with oral S-1 and 45 Gy IMRT had acceptable safety and efficacy in patients with locally advanced node-positive gastric cancer after radical gastrectomy and D1/D2 LND. The RD of oral S-1 was determined to be $80 \mathrm{mg} \mathrm{m}^{-2}$ day $^{-1}$ on radiotherapy days. The 3 -year DFS in patients who underwent S-1 chemotherapy at a dose of $80 \mathrm{mg} \mathrm{m}^{-2}$

Table 2. Dose-limiting toxicities in the phase I study $(N=27)$

\begin{tabular}{|l|c|c|c|c|c|}
\hline Level & $\begin{array}{c}\text { S-1 } \\
\text { (mg m }^{-2} \\
\text { day }^{-1} \text { ) }\end{array}$ & N & $\begin{array}{c}\text { Patients } \\
\text { with } \\
\text { DLT }\end{array}$ & DLT (G3) & $\begin{array}{c}\text { Radiotherapy } \\
\text { dose when DLT } \\
\text { occurred (Gy) }\end{array}$ \\
\hline I & 30 & 6 & 1 & Nausea, anorexia & 39.6 \\
\hline II & 40 & 3 & 0 & - & - \\
\hline III & 50 & 6 & 1 & Thrombocytopenia & 45 \\
\hline IV & 60 & 3 & 0 & - & - \\
\hline V & 70 & 3 & 0 & - & - \\
\hline VI & 80 & 6 & 0 & - & - \\
\hline Abbreviation: DLT =dose-limiting toxicity.
\end{tabular}


Table 3. Overall toxicities at the recommended dose in phases I and II of the study $(\mathbf{N}=52)$

\begin{tabular}{|l|c|c|}
\hline Toxicity & Grades $\mathbf{1 - 2}(\mathbf{N}, \boldsymbol{\%})$ & Grades 3-4 (N, \%) \\
\hline Nausea & $33(63.5)$ & $5(9.6)$ \\
\hline Vomiting & $12(23.1)$ & $3(5.7)$ \\
\hline Anorexia & $30(57.7)$ & $5(9.6)$ \\
\hline Oesophagitis & $10(19.2)$ & $2(3.8)$ \\
\hline Diarrhoea & $2(3.8)$ & 0 \\
\hline Abdominal pain & $2(3.8)$ & 0 \\
\hline Stomatitis & $13(25.0)$ & $1(1.9)$ \\
\hline Fatigue & $29(55.8)$ & $1(1.9)$ \\
\hline Weight loss & $6(11.5)$ & 0 \\
\hline HFS & $4(7.7)$ & 0 \\
\hline Leukopenia & $37(71.1)$ & $6(11.5)$ \\
\hline Neutropenia & $25(48.1)$ & $2(3.8)$ \\
\hline Anaemia & $11(21.2)$ & 0 \\
\hline Thrombocytopenia & $27(51.9)$ & 0 \\
\hline ALT/AST & $1(1.9)$ & 0 \\
\hline $\begin{array}{l}\text { Abbreviations: ALT =alanine aminotransferase; AST=aspartate aminotransferase; HFS }= \\
\text { hand foot syndrome. }\end{array}$ &
\end{tabular}

day $^{-1}$ was $62.2 \%$, which did not meet the primary end point of our phase II study.

In China, more and more surgeons have begun performing D2 LND because this is the most widely accepted surgical procedure in Asian and European countries (Bonenkamp et al, 1999). In our previous retrospective study of 297 patients with advanced gastric cancer who underwent radical surgery alone, in our specialised cancer hospital between 2002 and 2004, the median number of lymph nodes resected was 18 (range, 4-68 nodes), and the 5-year locoregional recurrence rate was $27.6 \%$ (Wang et al, 2011). In the present study, the median number of lymph nodes resected was higher, at 31 nodes (range, 8-79 nodes). A large observational study of a US population-based database found that, in patients undergoing radical gastrectomy for gastric cancer, the survival rate significantly improved with an increase in the number of lymph nodes examined, even when as many as 40 lymph nodes were resected (Smith et al, 2005). Thus, theoretically, the greater number of lymph nodes resected in our study may have provided better locoregional control and possibly a survival advantage. However, this number is still much smaller than those reported by studies from Japan and Korea, in which high-quality D2 LND was performed with a median of $>40$ lymph nodes examined (Bang et al, 2012; Kim et al, 2012; Lee et al, 2012). Furthermore, the benefit of ACRT for patients with locally advanced gastric cancer who undergo D2 LND remains controversial. In the ARTIST trial, the locoregional recurrence rate in the adjuvant chemotherapy alone group was already relatively low (13\% at 5 years) even without ACRT. However, in the ARTIST trial, only $40 \%$ of patients had advanced gastric cancer (stages III and IV (M0), AJCC Sixth edition). On the basis of this, we can estimate that the locoregional recurrence rate might be higher than $15 \%$ in patients with stage III or IV (M0) gastric cancer, despite D2 LND, especially in patients outside Japan and Korea or those treated in low-volume general hospitals without much surgical experience in standard D2 LND. Therefore, it is still necessary to investigate the effect of ACRT on locoregional control in high-risk patients with advanced gastric cancer.

Chang et al (2012) analysed the patterns of regional recurrence after D2 LND in patients with pathological N3 stage gastric cancer, according to AJCC Seventh edition (the median number of PLNs was 13 , which amounted to $28 \%$ of the median number of all lymph nodes examined) and found that nodal recurrence was most commonly detected in lymph nodes at stations 16b, 16a, 12, 14, 13, and 9. Regardless of the location of the primary tumour, lymph nodes at stations $16 \mathrm{a}$ and $16 \mathrm{~b}$ were the most common recurrence sites. These results suggest that, in patients with many PLNs (for example, those with $\mathrm{N} 3$ disease), tumour recurrence commonly occurs in lymph nodes located outside the D2 LND field. Thus more prospective studies are required to determine the optimal radiation target volume in such patients and to minimise radiationrelated toxicities. The ARTIST-II trial that aims to determine the abovementioned targets in this specific subgroup of high-risk node-positive gastric cancer patients is ongoing, and we look forward to their results.

According to the National Comprehensive Cancer Network guidelines, 5-FU or capecitabine is recommended to be used concurrently with radiotherapy after R0 resection and D0/D1 LND for locally advanced gastric cancer. In East Asia, both capecitabine and S-1 have been approved as combination treatments or monotherapies for advanced gastric cancer and have replaced 5-FU (Bang et al, 2012). Our previous study determined that the MTD and RD of capecitabine was $800 \mathrm{mg} \mathrm{m}^{-2}$ twice daily when administered concurrently with IMRT for gastric cancer after surgery (Wang et al, 2014), which is similar to the dose used in the radiotherapy phase of the ACRT group in the ARTIST trial. S-1 has been widely used in China as the ACTS-GC and other studies have reported promising results of adjuvant treatment with S-1 in Asian patients with advanced gastric cancer (Sakuramoto et al, 2007; Koizumi et al, 2008). The RD of $80 \mathrm{mg} \mathrm{m}^{-2} \mathrm{day}^{-1}$ of S-1 from the present study is now being administered in a randomised phase II trial of neoadjuvant chemotherapy compared with S-1-based chemoradiotherapy in patients with locally advanced gastric cancer in our hospital (NCT02301481). From the preliminary results, the compliance with preoperative chemoradiotherapy was $93.3 \%$ for S-1 and $96.7 \%$ for radiation (Wang et al, 2016). However, Ajani et al $(2005,2010)$ have confirmed that the tolerated dose of S-1 is lower in white patients than in Japanese patients. It is most likely because the efficacy of CYP2A6 enzyme is higher in white patients than in Asian patients, which would cause the former to convert tegafur to fluorouracil relatively rapidly, thus achieving a higher area under the curve of fluorouracil than that observed in Asian patients. Therefore, S-1 is not routinely used in the West.

In the present phase II study, the 3-year DFS and OS were $62.2 \%$ and $70 \%$, respectively, which did not meet the primary end point of our study (3-year DFS, 70\%). The main reasons for this were probably the large number of PLNs found and the relatively low number of total lymph nodes resected during gastrectomy. The median number of PLNs was as high as 11.5 in our phase II study, and $80.8 \%$ of our patients had pathological stage III or IV (M0) cancer, according to the AJCC classification (Sixth edition). Second, D2 LND was not performed in all patients in this study. Despite the above, our results are still comparable to those of the ACRT treatment arm in previous clinical trials in which patients underwent D2 LND (Table 4). A Korean phase III study applying the INT-0116 protocol to patients with stage III or IV (M0) gastric cancer undergoing D2 LND showed that ACRT could provide an LRFS benefit and might subsequently improve DFS but not OS (Kim et al, 2012). The 5-year DFS and OS in the ACRT group were $60.9 \%$ and $65.2 \%$, respectively, in the intent-to-treat analyses. However, the patients in the phase II portion of our study had more PLNs than those in this Korean study (median, 11.5 vs 8). Recently, another Korean phase II trial evaluating adjuvant S-1/ cisplatin chemotherapy with concurrent S-1/radiotherapy in gastric cancer patients after D2 LND (63.1\% of patients had stage III or IV (M0) disease, with a median number of PLNs of 5.5) reported 3year DFS and OS rates of $65.2 \%$ and $76.1 \%$, which are similar to our results (Shim et al, 2016). 
Table 4. Results in the adjuvant chemoradiotherapy treatment arms of selected studies on patients with gastric cancer undergoing surgery and D2 lymph node dissection

\begin{tabular}{|c|c|c|c|}
\hline Author (year) & $\begin{array}{c}\text { Median no. of PLNs }{ }^{a} / \text { percentage of patients with stage III } \\
\text { or IV (MO) }{ }^{a}\end{array}$ & Regimen/technique & End point \\
\hline Shim, et al (2016) & $5.5 / 63$ & S-1 + 45 Gy/AP-PA & 3-year DFS 65.2\%, OS 76.1\% \\
\hline Kim, et al (2012) & $8 / 100$ & $\mathrm{FL}+45 \mathrm{~Gy} / \mathrm{AP}-\mathrm{PA}$ & 5 -year DFS $60.9 \%$, OS $65.2 \%$ \\
\hline Zhu, et al (2012) & $\mathrm{NM} / 71.2$ & $\mathrm{FL}+45 \mathrm{~Gy} / \mathrm{IMRT}$ & 5 -year DFS $45.2 \%$, OS $48.4 \%$ \\
\hline ARTIST (2012) & 3/42.1 & Capecitabine + 45 Gy/AP-PA & 3-year DFS 78.2\%, \\
\hline
\end{tabular}

In this study, the most common grade $3 / 4$ haematological and gastrointestinal toxicities were leukopenia (11.5\%) and nausea (9.6\%), which were relatively less frequent than those in the aforementioned studies (Kim et al, 2012; Lee et al, 2012; Park et al, 2015; Shim et al, 2016). The exclusion of the remnant stomach from the radiation field and the application of IMRT may lead to a relatively lower rate of severe haematological (leukopenia/neutropenia) and gastrointestinal (nausea/vomiting) toxicities. The two Korean studies, which irradiated the remnant stomach and used the AP-PA conventional radiation technique, reported leukopenia/ neutropenia in $17.4-19.6 \%$ of patients and nausea/vomiting in $17.4-28.2 \%$ of patients (Kim et al, 2012; Shim et al, 2016). Although the ARTIST trial did not routinely include the remnant stomach in the radiation field, it also reported that $48.4 \%$ and $12.3 \%$ of patients developed grade $3 / 4$ neutropenia and nausea, respectively. This may be attributable to the use of AP-PA, which is inferior to IMRT and associated with a greater risk of toxicity. Compared with infusional 5-FU, S-1 has similar efficacy and lower gastrointestinal toxicity in patients with advanced gastric cancer due to the active agent oteracil (which reduces the gastrointestinal toxicity of 5-FU) (Ajani et al, 2010). Given these reasons, the present study showed acceptable safety and comparable compliance with the treatment course, in which concurrent S-1 was totally completed as planned in $75 \%$ of patients (39 out of 52). The radiotherapy course was completed as planned in $94.2 \%$ of patients ( 49 out of 52).

The limitations of this study should also be considered. This is a single-institution study, and its sample size is not large enough to draw a definite conclusion on the survival benefit of ACRT with S-1 treatment for node-positive gastric cancer. Owing to the poor patient recruitment for this study, we did not limit the regimens or cycles of adjuvant chemotherapy administered before or after ACRT. Thus patients received differing adjuvant chemotherapy regimens depending on their oncologist's preference, which may have impacted the results. In addition, the patients were recruited postoperatively, thus generating a bias of selected subgroup of all patients undergoing surgery.

In conclusion, we consider that ACRT with $80 \mathrm{mg} \mathrm{m}^{-2}$ day $^{-1}$ oral S-1 twice daily combined with IMRT at a dose of at least $45 \mathrm{~Gy}$ in 25 fractions was safe and efficacious. The use of advanced techniques such as IMRT, an appropriate irradiation field, and low-toxicity single-agent chemotherapy regimens such as S-1 is highly recommended. A randomised phase III study in our hospital comparing adjuvant chemotherapy with S-1-based ACRT for node-positive locally advanced gastric cancer after D2 LND is ongoing (NCT02648841), and its results are eagerly awaited.

\section{ACKNOWLEDGEMENTS}

This work was supported by grants from the Capital Characteristic Clinic Project (grant number Z151100004015033) and the National Key Projects of Research and Development (grant number 2016YFC0904600).

\section{CONFLICT OF INTEREST}

The authors declare no conflict of interest.

\section{REFERENCES}

Ajani JA, Faust J, Ikeda K, Yao JC, Anbe H, Carr KL, Houghton M, Urrea P (2005) Phase I pharmacokinetic study of S-1 plus cisplatin in patients with advanced gastric carcinoma. J Clin Oncol 23(28): 6957-6965.

Ajani JA, Rodriguez W, Bodoky G, Moiseyenko V, Lichinitser M, Gorbunova V, Vynnychenko I, Garin A, Lang I, Falcon S (2010) Multicenter phase III comparison of cisplatin/S-1 with cisplatin/infusional fluorouracil in advanced gastric or gastroesophageal adenocarcinoma study: the FLAGS trial. J Clin Oncol 28(9): 1547-1553.

Bang YJ, Kim YW, Yang HK, Chung HC, Park YK, Lee KH, Lee KW, Kim YH, Noh SI, Cho JY, Mok YJ, Kim YH, Ji J, Yeh TS, Button P, Sirzen F, Noh SH (2012) Adjuvant capecitabine and oxaliplatin for gastric cancer after D2 gastrectomy (CLASSIC): a phase 3 open-label, randomised controlled trial. Lancet 379(9813): 315-321.

Bonenkamp JJ, Hermans J, Sasako M, van de Velde CJ, Welvaart K, Songun I, Meyer S, Plukker JT, Van Elk P, Obertop H, Gouma DJ, van Lanschot JJ, Taat CW, de Graaf PW, von MMF, Tilanus H (1999) Extended lymphnode dissection for gastric cancer. $N$ Engl J Med 340(12): 908-914.

Chang JS, Lim JS, Noh SH, Hyung WJ, An JY, Lee YC, Rha SY, Lee CG, Koom WS (2012) Patterns of regional recurrence after curative D2 resection for stage III (N3) gastric cancer: implications for postoperative radiotherapy. Radiother Oncol 104(3): 367-373.

Japanese Gastric Cancer Association (1998) Japanese Classification of Gastric Carcinoma, 2nd English edition. Gastric Cancer 1: 10-24.

Kim TH, Park SR, Ryu KW, Kim YW, Bae JM, Lee JH, Choi IJ, Kim YJ, Kim DY (2012) Phase 3 trial of postoperative chemotherapy alone versus chemoradiation therapy in stage III-IV gastric cancer treated with R0 gastrectomy and D2 lymph node dissection. Int J Radiat Oncol Biol Phys 84(5): e585-e592.

Koizumi W, Kurihara M, Nakano S, Hasegawa K (2000) Phase II study of S-1, a novel oral derivative of 5-fluorouracil, in advanced gastric cancer. For the S-1 Cooperative Gastric Cancer Study Group. Oncology 58(3): 191-197.

Koizumi W, Narahara H, Hara T, Takagane A, Akiya T, Takagi M, Miyashita K, Nishizaki T, Kobayashi O, Takiyama W, Toh Y, Nagaie T, Takagi S, Yamamura Y, Yanaoka K, Orita H, Takeuchi M (2008) S-1 plus cisplatin versus S-1 alone for first-line treatment of advanced gastric cancer (SPIRITS trial): a phase III trial. Lancet Oncol 9(3): 215-221.

Lee J, Lim dH, Kim S, Park SH, Park JO, Park YS, Lim HY, Choi MG, Sohn TS, Noh JH, Bae JM, Ahn YC, Sohn I, Jung SH, Park CK, Kim KM, Kang WK (2012) Phase III trial comparing capecitabine plus cisplatin versus capecitabine plus cisplatin with concurrent capecitabine radiotherapy in completely resected gastric cancer with D2 lymph node dissection: the ARTIST trial. J Clin Oncol 30(3): 268-273.

Macdonald JS, Smalley SR, Benedetti J, Hundahl SA, Estes NC, Stemmermann GN, Haller DG, Ajani JA, Gunderson LL, Jessup JM, Martenson JA (2001) Chemoradiotherapy after surgery compared with surgery alone for adenocarcinoma of the stomach or gastroesophageal junction. $N$ Engl J Med 345(10): 725-730. 
Park SH, Sohn TS, Lee J, Lim dH, Hong ME, Kim KM, Sohn I, Jung SH, Choi MG, Lee JH, Bae JM, Kim S, Kim ST, Park JO, Park YS, Lim HY, Kang WK (2015) Phase III trial to compare adjuvant chemotherapy with capecitabine and cisplatin versus concurrent chemoradiotherapy in gastric cancer: final report of the adjuvant chemoradiotherapy in stomach tumors trial, including survival and subset analyses. J Clin Oncol 33(28): 3130-3136.

Sakuramoto S, Sasako M, Yamaguchi T, Kinoshita T, Fujii M, Nashimoto A, Furukawa H, Nakajima T, Ohashi Y, Imamura H, Higashino M, Yamamura Y, Kurita A, Arai K (2007) Adjuvant chemotherapy for gastric cancer with S-1, an oral fluoropyrimidine. N Engl J Med 357(18): 1810-1820.

Schöffski P (2004) The modulated oral fluoropyrimidine prodrug S-1, and its use in gastrointestinal cancer and other solid tumors. Anticancer Drugs 15(2): 85-106.

Shim HJ, Kim KR, Hwang JE, Bae WK, Ryu SY, Park YK, Nam TK, Chung IJ, Cho SH (2016) A phase II study of adjuvant S-1/cisplatin chemotherapy followed by S-1-based chemoradiotherapy for D2-resected gastric cancer. Cancer Chemother Pharmacol 77(3): 605-612.

Smith DD, Schwarz RR, Schwarz RE (2005) Impact of total lymph node count on staging and survival after gastrectomy for gastric cancer: data from a large US-population database. J Clin Oncol 23(28): 7114-7124.

Trip AK, Nijkamp J, van Tinteren H, Cats A, Boot H, Jansen EP, Verheij M (2014) IMRT limits nephrotoxicity after chemoradiotherapy for gastric cancer. Radiother Oncol 112(2): 289-294.

Tsuburaya A, Yoshida K, Kobayashi M, Yoshino S, Takahashi M, Takiguchi N, Tanabe K, Takahashi N, Imamura H, Tatsumoto N, Hara A, Nishikawa K, Fukushima R, Nozaki I, Kojima H, Miyashita Y, Oba K, Buyse M, Morita S, Sakamoto J (2014) Sequential paclitaxel followed by tegafur and uracil (UFT) or S-1 versus UFT or S-1 monotherapy as adjuvant chemotherapy for T4a/b gastric cancer (SAMIT): a phase 3 factorial randomised controlled trial. Lancet Oncol 15(8): 886-893.

Wang X, Jin J, Li YX, Ren H, Fang H, Wang SL, Liu YP, Wang WH, Yu ZH, Song YW, Liu XF (2014) Phase I study of postoperative radiotherapy combined with capecitabine for gastric cancer. World J Gastroenterol 20(4): 1067-1073.

Wang X, Jin J, Li YX, Wang SL, Wang WH, Song YW, Liu YP, Liu XF, Yu ZH (2011) Analysis of recurrence for locally advanced gastric or gastroesophageal cancer patients after receiving curative gastrectomy ( $>$ D1) and its indication for adjuvant chemoradiotherapy. Chin J Radiat Oncol 20(2): 133-141.

Wang X, Zhao DB, Jin J, Chi Y, Yang L, Tang Y, Che X, Zhao H, Jiang LM, Ren H, Liu WY, Li N, Li YX (2016) A randomized Phase II trial of neoadjuvant chemotherapy compared with chemoradiation therapy in locally advanced gastroesophageal and gastric adenocarcinoma: preliminary results. Int J Radiat Oncol Biol Phys 96(2): S32.

Zhu WG, Xua DF, Pu J, Zong CD, Li T, Tao GZ, Ji FZ, Zhou XL, Han JH, Wang CS, Yu CH, Yi JG, Su XL, Ding JX (2012) A randomized, controlled, multicenter study comparing intensity-modulated radiotherapy plus concurrent chemotherapy with chemotherapy alone in gastric cancer patients with D2 resection. Radiother Oncol 104(3): 361-366.

This work is published under the standard license to publish agreement. After 12 months the work will become freely available and the license terms will switch to a Creative Commons AttributionNonCommercial-Share Alike 4.0 Unported License.

Supplementary Information accompanies this paper on British Journal of Cancer website (http://www.nature.com/bjc) 